\title{
Sürdürülebilir Kentleşme Ekseninde Kamusal Mekânın Kentsel İç Mekâna Dönüşümü: Helsinki Örneği
}

\author{
$*$ \\ Gamze Karayılanoğlu ${ }^{1}$ \\ ORCID: 0000-0002-7874-4902
}

\section{Öz}

Bu çalışma kentsel iç mekân kavramı ile bağlantı kurarak kamusal iç mekânı kentsel alanın bir uzantısı olarak ele almaktadır. Sürdürülebilir kentleşme politikaları izleyen gelişmiş kentlerde kültür mekânlarn bölgesel dönüşüm projelerinin temelini oluşturmaktadır. Kentsel iç mekân kavramı, bu bağlamda araştırılmak üzere belirlenen Helsinki kentinde seçilen dönüşüm projesi ile kültürel kalkınma ve sürdürülebilir kentleşme ekseninde irdelenmiştir. Saha araştırması ile incelenen Helsinki Lasipalatsi Meydanı ve Amos Rex Yeraltı Müzesi'nin tarihsel bağlamı, kentle ilişkisi ve dönüşümüne odaklanarak, kentsel iç mekânın katmanları üzerine çözümlemeler sunulmuştur. Kent meydanı ile bağlantılı tasarlanan müze örneği üzerinden kamusal alanın iç mekânla ilişkilenerek kentsel iç mekâna dönüşümü, sürdürülebilir kentleşme ve kültürel kalkınma kavramsal çerçevesinde ele alınmıştır. Bu çalışma ile, sürdürülebilir kent politikaları kapsamında tasarlanan kent meydanındaki çok işlevli dönüşümün özellikleri, kamusal iç mekân ve kentsel iç mekân arasındaki sınırların hangi yöntemlerle silikleştiği ve katmanlı bir mekân deneyiminin koşulları tartışılmaktadır. Araştırma sonucunda; meydanın kentsel iç mekâna dönüşümünü sağlayan başlıca etmenin, kamusal iç mekân olan müze ile görsel ve dokunsal olarak katmanlı ilişkiler içerisinde tasarlanması olduğu görülmüştür.

Anahtar Kelimeler: Kentsel iç mekân, kamusal mekân, kültürel kalkınma, sürdürülebilir kentleşme, Helsinki.

\footnotetext{
${ }^{1}$ Arş. Gör. Dr., Mimar Sinan Güzel Sanatlar Üniversitesi, E-mail: gamze.karayilanoglu@msgsu.edu.tr idealkent (c) Kent Araştırmaları Dergisi (Journal of Urban Studies) 


\title{
Transformation of Public Space into Urban Interior on the Axis of Sustainable Urbanization: The Case of Helsinki
}

\author{
Gamze Karayılanoğlu² \\ ORCID: 0000-0002-7874-4902
}

\begin{abstract}
This study deals with the concept of urban interior by taking the public interior as an extension of the urban space. In developed cities, cultural spaces form the basis of regional transformation projects. This study aims to examine the concept of urban interior in the axis of cultural development and sustainable urbanization through the transformation in the city center of Helsinki. Public space and urban interior concepts are analysed through a literature review. Field research was conducted at Helsinki Lasipalatsi Square and Amos Rex Underground Museum. The area is examined by focusing on its historical context, its relationship with the city and, its transformation. The study discusses the features of the multi-functional transformation of public square designed within the scope of sustainable urban policies, the methods that blur the boundaries between the public interior and the urban interior, and the conditions of a layered spatial experience. As a result, the study shows that the main factor that transforms the public square into an urban interior is its design in visual and tactile layered relationships with the museum space.
\end{abstract}

Keywords: Urban interior, public space, cultural development, sustainable urbanism, Helsinki.

\footnotetext{
${ }^{2}$ Res. Assist. Dr., Mimar Sinan Fine Arts University, E-mail: gamze.karayilanoglu@msgsu.edu.tr idealkent (c) Kent Araştırmaları Dergisi (Journal of Urban Studies) 


\section{Giriş}

İç mekânlar genellikle mimari yapıların strüktürleri içerisinde kalan alanlar olarak tanımlansa da kent organizmasını oluşturan her bir öğenin birbirleriyle ilişkisi sonucu ortaya çıkan alanlar, arayüzler, aralıklar, eşikler bazen birer iç mekân halini alabilir. Bruno Zevi (1957) mimari mekânı iç mekânla tanımlamıştır. Ona göre mimari mekân içine girilip yürünebilen, içinde yaşanabilen içi boş, büyük bir heykel gibidir. Mimari mekânlar ancak iç mekânlar ile tümüyle deneyimlenebilmektedir. Zevi, bu noktada iç mekânla neyi kastettiğini tanımlamaktadır:

Mimarlı̆̆ özgü mekân deneyimi, içerisinde kenti, sokakları, meydanları, dar sokakları ve parkları, oyun alanlarını ve bahçeleri, insanın eserinin boşluklara sınırlar getirdiği, yani kapalı mekânlarla tanımladığı her yeri barındırır. Eğer bir binanın içerisinde mekân altı düzlemle (zemin, tavan ve dört duvar) sınırlandırllyorsa, bu altı yerine beş düzlemle kapatılmış bir mekânın -örneğin (çatısız) bir avlu ve halk meydanı gibi- kapalı bir mekân olmadığı anlamına gelmez (Zevi, 1957, s. 29).

Zevi, mekânsal deneyimin birincil alanı olarak iç mekânı belirlese de dış mekânı onu oluşturan mimari yapılar ve bölüntüler ile birer iç mekân olarak tanımlamıştır. Ona göre mekân deneyimi kentle ilişkili bütüncül bir kavramdır. Le Corbusier'nin (1929) “Dışarısı bir içerinin sonucudur.” sözü de benzer bir fikri anlatmaktadır. Farklı ölçeklerde, dış mekânların da birer ortak kullanım alanı olarak kentsel iç mekânlar oluşturduğunu ifade etmektedir. Mekân deneyimi dış ve iç mekânın birlikteliğiyle şekillenen bütüncül bir süreci tanımlamaktadır. Bu ilişkilerin kurgulanma şekli kentsel deneyimi şekillendirmektedir.

Kentleri oluşturan dinamikler yapı blokları, yollar, kesişim noktaları, odak noktaları, peyzaj alanları gibi pek çok farklı işlevde ve çok çeşitli niteliklere sahip kullanıcılara hizmet eden öğelerdir (Lynch, 2010). Sürekli değişip dönüşen kentsel ihtiyaçlar ve kullanıcı çeşitliliği göz önüne alındığında geleceğin kentlerinin tasarımı konusunda alınan kararların önemi ortaya çıkmaktadır. Gardner'a (2016) göre, "sürdürülebilir bir kent, tüm vatandaşları için onurlu yaşama imkânı sunmak için doğal çevre ile uyum içinde, geniş fırsatlar sunan hareketli bir insan yerleşimidir". Gardner'ın sözünü ettiği bu şartların nasıl sağlanacağına yönelik geniş kapsamlı bir literatür mevcut olmakla birlikte, uluslararası ölçekte çalışmalar yapılmaktadır. Birleşmiş Milletler' in 'Sürdürülebilir Kalkınma Amaçları' olarak tanımladığı 17 maddelik kalkınma planının 11. maddesi kentleri kapsamaktadır. Bu madde, kentlerde 
gittikçe artan nüfus oranlarıyla birlikte oluşan yoksulluk, sosyal adaletsizlik, kaynakların dengesiz dağılımı gibi olumsuz koşulları dengeleyerek kapsayıcl, güvenli ve sürdürülebilir kentler oluşturma hedefi taşımaktadır (United Nations Development Programme, 2016). Artan kentsel nüfus, yeni yerleşim alanlarına ihtiyaç doğurmakta, bu ihtiyaç da kentin dış çeperlerinin çoğunlukla çarpık kentleşmeyle genişlemesi ile sonuçlanmaktadır. Bu kontrolsüz genişlemenin sonucunda ulaşım koşulları düşünülmemiş yerleşim bölgeleri, yaşam standardı düşük kentliler ve çevreye ve iklime zarar veren kısa vadeli çözümler üreten kentler ortaya çıkmaktadır. Birbirini tetikleyen bu zorlukların üstesinden gelmenin yöntemi yerel yönetimlerin, kentlilerin ihtiyaçlarını ve kırılganlıklarını en iyi anladıkları kent düzeyindedir (Jarvie ve Friend, s. 344). Bu bilinç düzeyini sürdürülebilir şekilde sağlamak ise kültürel kalkınmadan geçmektedir.

2030 yılına kadar gerçekleştirilmesi hedeflenen amaçlar çerçevesinde ön plana çıkan başlıca konulardan biri kültürel kalkınmadır. Bu amaçla kültürel miras, yaratıcı endüstriler, yerel kültür ve ürünler, yerel topluluklar, yerel malzemeler ve kültürel çeşitliliğin desteklenmesi, toplumun karar alma sürecine katılımı gibi konular vurgulanmaktadır (United Nations Educational, Scientific and Cultural Organization, 2019, s. 13). Birleşmiş Milletler' in 'Kültür ve Sürdürülebilir Kentleşme' adlı raporunda kültür; "insan deneyiminin içsel bir parçası, ruhun oksijeni" olarak tanımlanmış, kimlik ve aidiyet kaynağı olarak küresel ve yerel düzeydeki kalkınma için önemi vurgulanmıştır.

Bir başka örnekte, kültürün sürdürülebilir kentleşme yolunda önemi, Birleşmiş Milletler' in düzenlediği Habitat III sonucunda sunulan 'Yeni Kentsel Gündem' bildirisinin 10. maddesi ile açıkça dile getirilmektedir:

Yeni Kentsel Gündem kültürün ve kültürel çeşitliliğin insanllğı zenginleştiren kaynaklar olduğunu ve kentlere, insan yerleşimlerine ve vatandaşlara kalkınma girişimlerinde aktif ve eşsiz bir rol oynama imkânı tanıyarak sürdürülebilir kalkınmalarına önemli bir katkı sağladığını kabul etmektedir. Yeni Kentsel Gündem, kaynakların sorumlu kullanımına katkıda bulunan ve iklim değişikliğinin olumsuz etkilerini ele alan yeni sürdürülebilir tüketim ve üretim kalıplarının geliştirilmesi ve uygulanmasında kültürün dikkate alınması gerektiğini de kabul etmektedir (United Nations, 2016).

Bu bağlamda kültürün toplumlara aktarımında kurumsal mekânların başında gelen müzeler, geleceğin sürdürülebilir kentleşme öngörüsünde kritik bir öneme sahiptir. Uluslararası Müzeler Konseyi (ICOM), 2017 yılında yayınlanan bildirgesinde müzeyi; “Toplumu geliştirmek için kamu yararı adına 
hizmet veren, halka açı, insanlığın ve çevresinin somut ve soyut kültürel mirasını eğitim, çalışma ve eğlence amaçları için toplayan, koruyan, araştıran, ileten ve sergileyen kalıcı bir kurum" olarak tanımlamıştır. Bu tanım, yukarıda bahsedilen sürdürülebilir kalkınma amaçlarında olduğu gibi toplumsal hayatı etkileyen gelişmeler ışığında yeniden gündeme alınmış ve revize edilmesi gündeme gelmiştir. ICOM Yürütme Kurulu, Temmuz 2019'da müzenin yeni, alternatif tanımını sunmuştur:

Müzeler geçmiş ve gelecek hakkında eleştirel diyalog oluşturmak amacıyla demokratikleştirici, kapsayıcı ve çok sesli alanlardır. Günümüzün çatışmalarını ve zorluklarını kabul ederek ve ele alarak, toplum adına sanat eserlerini ve kültürel objeleri barındırır, gelecek nesiller için çeşitli anıları korurlar ve tüm insanlık için eşit hakları ve kültürel mirasa erişimi garanti ederler. Müzeler kâr amacı gütmezler. Katılımcı ve şeffaftırlar. İnsan onuruna ve sosyal adalete, küresel eşitliğe ve esenliğe katkıda bulunmayı amaçlayarak dünya anlayışlarını biriktirmek, korumak, araştırmak, yorumlamak, sergilemek ve geliştirmek için çeşitli topluluklarla aktif ortaklıklar içinde çalışırlar (International Council of Museums, 2019).

Müze mekânlarına atfedilen bu nitelikler kültürün üretimi ve aktarımı konusunda bu yapıların kamuya açık, şeffaf ve eğitici niteliklerini ön plana çıkarmaktadır. Bu bağlamda müze yapılarının kent içerisindeki fiziki konumu, çevresiyle ilişkisi ve mimari kimliği oldukça önemli hale gelmektedir. Kentliler için bir anlamda "açık fikir platformu" görevi görebilecek müzelerin kent merkezlerinde, kamuya açık, kolay erişilen, şeffaf, kullanıcı odaklı, ortak mekânlar olarak kurgulanması gerekmektedir. Bölgesel ve küresel kimliğin korunarak kültürel mirasa erişimin kolaylaştırıldığı mekân tasarımları bu ilişkiler sistemini gerçekleştirmek için anahtar olacaktır. Geleneksel müze mekânlarının kapalı kapılar ardında kültürel miras öğelerini koruduğu içe dönük sisteminin yerini kente açlan, kentliyle birlikte gelişen kamusal iç mekânla kentsel mekânı birleştiren alanlar haline gelmesi önemlidir.

Lynch (2010) kent içerisinde hiçbir öğenin kendiliğinden deneyimlenemeyeceğini ve her öğenin çevresindekilerle bağı olduğunu vurgular. Kent organizmasında bütünü oluşturan parçaların her biri birbirleriyle ilişkilidir. Lynch'in kentteki odak noktaları olarak tanımladığı kent meydanları da bu bağlamda kendisini oluşturan çevresel öğelerle bütüncül bir ilişki içerisindedir. Kent meydanları, çok çeşitli kimlik ve karakterlere sahip çok sayıda kullanıcının kent içerisinde ortak aktivitelerde kullandığı kamusal mekânlardır. Meydanlar, çevreleriyle ilişkileri ve organizasyonları bakımından aynı zamanda kentsel iç mekân kimliği taşımaktadırlar. 
Bu çalışma kapsamında; kamusal bir iç mekân olan müze ile, kentsel bir iç mekân olan kent meydanı ilişkisi sürdürülebilir kentleşme bağlamında ele alınmıştır. Helsinki kent merkezinde yer alan Lasipalatsi Meydanı ve Amos Rex Yeraltı Müzesi, kentsel iç mekân-kamusal mekân arakesitindeki katmanlı ilişkileri bakımından incelenmek üzere seçilmiş, literatür taraması ve saha araştırması yöntemiyle vaka analizi yapılmıştır.

\section{Kavramsal Çerçeve}

Kamusal mekân ve kentsel iç mekânı tanımlamak için önce mekânı, sonrasında neyin mekân, neyin iç mekân olarak tanımlanabileceğini tartışmak gerekir. Kant, mekân ve zamanı verilmiş sonsuz bir büyüklük olarak tasavvur eder. Ona göre mekân ve zamanın kaynağı süjedir. Mekân dış duyunun, zamansa iç duyunun formlarıdır (Akarsu, 2014). Fiziksel ve maddi çevrenin insan bilincinde anlamlı hale gelmesi, fenomenolojik metodun öncüleri Edmund Husserl ve Maurice Merleau-Ponty'nin çalışmalarında kritik bir öneme sahiptir. Husserl ve Merleau-Ponty'ye göre mekânı oluşturan bedensel yönelim ve insan bilincidir (Archer, 2005). Heidegger'e göre ise mekân kendi başına hiçbir şey değildir ve mutlak mekân diye bir şey yoktur. Mekân ancak içerdiği cisimler ve enerjilerle var olur (Nalbantoğlu, 2008). Mimarinin konusu olan mekân kavramı ise, felsefeden farklı olarak -felsefede sonsuz ve sınırsız evren de mekân olarak adlandırılabilmektedir- iç mekân, kentsel mekân gibi farklı ölçeklerde ele alınabilmektedir. (Kahvecioğlu, 1998, s. 40).

Steven Holl'e (2000) göre ise mekân; bireyin duyularıla algıladığı, zamanla ve deneyimle ilişkilenerek tanımlanabilen, soyut ve somut kavramlar bütünüdür. Ona göre mekân; mimarideki boşluklar, mimari mekânı çevreleyen alan, geniş peyzajlar, kentsel alan ve evrenin galaksiler arası alanları gibi çok farklı ölçeklerle ifade edilebilmektedir (Holl, 2000). Mekân hem içsel hem de ilişkisel bir kavramdır. Kişinin algısıyla, yaklaşımıyla ve kurduğu ilişki ile farklı tanımlar elde edebilmekte, zamanla değişen bir deneyim sunabilmektedir.

Tüm bu yaklaşımlar ışığında, mekânın tanımlanması birey tarafından algılanışına, bu algılama da mekânın ölçeğine bağlı olarak değişim göstermektedir. İç mekân olarak tanımlanan, sınırlı ve 'kapalı' alan yalnızca yapıların içi olmak zorunda değildir. Kent içerisinde farklı ölçeklerde öğelerle sınırlanmış açık alanlar da iç mekân olarak algılanabilmektedir. Kentin tıpkı evlerimiz gibi temas edebildiğimiz, boyutlarını algılayabildiğimiz parçaları kentsel iç mekânlar halini alırlar. İç mekân ve dış mekân algıladığımız ölçüde iç içe geçer ve dönüşür. 


\section{Kamusal Mekân Kavramı}

Kamusal mekân ya da diğer bir deyişle kamusal alan kentsel iç mekânları da kapsayan, kitle kültürü ile şekillenen ve erişime açık 'ortak' bir alanı tanımlar. Kamusal alan yaklaşımlarının kökeni Antik Yunan'a dayanmaktadır. Kentleri oluşturan politik ve sosyo-kültürel ilişkilerle şekillenen kamusal mekânlar agoralar, salonlar, kent meydanları, pazar yerleri gibi tarihsel süreçte farklı şekillerde kurgulanmıştır (Odabaş, 2018). Toplulukların bir araya geldiği, çoğulcu bir ortam yaratmaları sebebiyle aynı zamanda geçmişten beri toplumsal ve siyasi bir değere sahiptirler.

Kavram 1950-1960'lı yıllar arasında ortak alan tanımı ile ortaya çıkmıştır. Kamusal alan kavramı üzerine tartısmalar ise ilk kez 1962 yılında, Habermas'ın Kamusallığın Yapısal Dönüşümü adlı eseri ile başlamıştır. Habermas, kamusallık kavramın tarihsel, fiziksel ve sembolik nitelikleri üzerinden tanımlamıştır. Kamu, kamusallık, kamuoyu, kamusal alan gibi kavramların tarihsel dönüşümünü değerlendirirken, cadde, meydan, sokak gibi oluşumların nasıl meydana geldiğini ele almıştır. Bu mekânlarda toplumun düşüncelerini, eylemlerini ve bunun siyasal yönünü sorgulamıştır (Gökgür, 2008; Odabaş, 2018). Gökgür (2008), 'Kentsel Mekânda Kamusal Alanın Yeri' adlı eserinde kavramın çeşitli düşünürlerce farklı yorumundan şöyle bahsetmektedir:

Thierry Paquot, felsefi bir kavram olarak ele alır ve kamusal ortam olarak nitelendirir, Sennett ise maddi bir alan olarak ele almaktadır. Max Weber çeşitli insanların karşlaşma alanı olarak görürken, D. Wolton başlangiçta fizikselken zamanla sembolik bir alana dönüştügünü savunmuştur. Günümüzde ise kamusal alanlar, insanların kentlerde yoğunlaşması sebebiyle yeniden yapılandırılmaya başlamıştır. Yeniden yapılandırma, özelleştirmeye ve standartlaştırılmaya neden olmaktadır ve kamusal alanın özelliklerinin yitirilmesine neden olmaktadır.

Lefebvre (2014) ise, kamusal alanları toplumsal mekân kavramı ile sınıflandırmaktadır. Ona göre "toplumsal mekân formu buluşmadır, bir araya gelmedir, kendiliğindenliktir." (Lefebvre, 2014, s.125). Kent içerisinde farklı ölçeklerde kesişim ve buluşma noktaları halini alan kent meydanları, sürekli bir devinim halindeki toplumsal mekânlardır.

Kamusal alana yapılan her müdahale o yere ait kimliğin farklı açılardan değişimine sebep olur. Kamusal alanın özelliklerini yitirmesine neden olan müdahaleler genellikle kentlilerin fikirlerinin alınmadığı, tepeden inme kararlarla gerçekleşmektedir. Bu bağlamda kent meydanları gibi halkın ortak 
kullanım alanı olan kamusal mekânlarda yapılan düzenlemeler çoğulcu ve kentlilerin ihtiyaçları çerçevesinde alınan kararlarla şekillenmelidir. Kolektif kullanım alanları olan kamusal mekânlar, çoğulcu bir yaklaşımla kurgulandığında bulunduğu kentin ve çevrelediği toplulukların kültürel ve tarihsel değerlerini koruyan ve içeren bir kimliği de beraberinde taşımaktadır.

Kamusal mekânlar kent organizmasında dış mekânlar olabildiği gibi, ortak kullanım alanı niteliği taşıyan ve çoğunlukla kurumsal, halka açık iç mekânlar da olabilmektedir. Sinema salonları, müzeler, kafeler, restoranlar, kahvehaneler, kütüphaneler gibi kentlilerin bir arada kullanabildiği, özel olmayan iç mekânlar kamusal iç mekânlardandır. Kamusal alanın buluşturucu etkisi bu mekânlarda devam etmektedir. Bu süregeliş hali iç-dış ilişkileri ile kamusal mekânı bir bütün kılar ve geçiş noktaları, eşikler oluşturur. Kamusal dış mekânla, örneğin bir meydanla kesişen kamusal iç mekânlar liminal bir bölge oluşturur. Bu liminal bölge, aynı kullanıcıya hizmet etmesi ve bağlamsal kimliği ile kamusal alanda kentsel iç mekânları meydana getirir.

\section{Kentsel İç Mekân Kavramı}

İç mekân tasarımının kapalı mekânlarda gerçekleşmesi gerektiği önyargısına rağmen, kent ve iç mekân kavramı arasındaki ilişkisel duruma odaklanarak, iç mekân tasarlama pratiğinin düşünme ve uygulama tekniklerini kente uyarlayan bir yaklaşım mümkündür (Attiwill, 2011). Günümüz kentlerinde özel ve kamusal alanlar arasındaki ayrık ilişki dönüşüme uğramaktadır. Kent plancısı ve mimar Harteveld ve Brown (2007) son yıllarda bina içlerindeki kamusal alan oranlarının gittikçe arttığını ve bunun büyük kısmını daha geniş bir iç ve dış mekânla bağlantılı yaya kullanımlı alanların kapsadığını ifade etmektedir (akt. Poot ve diğ., 2015). Kent meydanları, bir üst örtü ile sınırlandırılmış sokak araları, binalar arasındaki boşluklar, viyadük ayakları arasında oluşan âtıl mekânlar gibi kent içerisinde herkesin kullanımına açık ya da arada kalmış bu gibi mekânlar kentsel iç mekânlardır. Dış mekânların mekânsal dönüşüm yoluyla iç mekâna dönüştüğü kentsel dokuyu değiştirme teknikleri ile, kentsel bir iç mekân kolayca kavranmaktadır (Attiwill, 2011, s.15). Attiwill (2011), kentsel iç mekânı “İnsanların yaşam alanları içinde gerçekleştirdikleri yaşama, çalışma, oyun oynama, satış, sergileme ve benzeri eylemlerin dış mekâna taşmasıyla söz konusu aktivitelere ev sahipliği yapan geçici, deneysel ve deneyimsel alanlar" olarak tanımlamaktadır (aktaran Cordan ve Çolak, 2015). Buna göre kentsel iç mekânlar, özelden kamusala geçişte ortak kullanım alanı halini alan, özel ve kamusal arasındaki geçişin silikleştiği 
alanlar olarak işlemektedir. Bu alanlar bazı kaynaklarda kentsel arayüzler olarak da tanımlanmaktadır. Özyörük (1995) arayüzleri; “Görsel ve işlevsel olarak kamusal dış mekânlar ile özel iç mekânlar arasında iç-dış bağlantısını kuran, kentsel dokuyu nasıl okuyacağımızı belirleyen mimari yapı biçimleri ile kentsel kamusal dış mekânlar arasındaki geçişim bölgeleri" olarak tanımlamaktadır (akt. Bala, 2006, s. 293). Bu geçişim bölgeleri, tıpkı iç mekânlarda olduğu gibi, kendilerini çevreleyen yapılarla sınırlanarak kapalı bir hacim hissini vermektedir.

Dış-iç mekân karşıtlığının algı zemininde bir araya geldiği kentsel iç mekân kavramı, tam da bu arada kalmış durumdan beslenmektedir. Kapalı ve genellikle özel mekânlarla özdeşleştirilen iç mekân kavramının kamusal ve açık mekânda hissedildiği ve çevresindekilerle ilişkilenerek farklı bir ölçekte iç mekânlaştığı bir kent olgusudur. Altınyıldız Artun (2014) kenti, "evin uzantısı, modern bilinçdışının mekânı" olarak tanımlamaktadır. Bu söylem, ev gibi kapalı, özel/mahrem bir iç mekânın uzantısı olan kentin kesişim noktalarını, sahip olduğu aradalık ve geçişli hal ile kentsel iç mekânla ilişkilendirmektedir.

\section{Alan Çalışması: Helsinki Lasipalatsi Meydanı ve Amos Rex Yeraltı Müzesi}

Finlandiya'nın başkenti Helsinki; Alvar Aalto, Juhani Pallasmaa, Steven Holl, Eero Saarinen, Aino Aalto gibi dünyaca ünlü pek çok modern ve çağdaş mimarın üretimlerinin kent kimliğine etki ettiği düzenli bir kenttir. Ancak kent yalnızca ünlü mimarların bireysel eserlerinden oluşmadı̆̆ gibi Helsinki kenti için de durum sadece bundan ibaret değildir. Ekonomik İşbirliği ve Kalkınma Örgütü'nün (OECD) verilerine göre Helsinki'nin bölgesel kalkınma oranları on başlık altında ölçülmüştür (Organisation for Economic Co-operation and Development, 2019). Bu başlıklar; maddi gelir, iş imkanları, barınma, sağlık, hizmetlere erişim, çevre, eğitim, güvenlik, sivil katılım ve yönetişim, komünite ve yaşam memnuniyeti olarak belirlenmiştir. On üzerinden belirlenen verilere göre Helsinki ve Uusima bölgesinin kalkınma seviyesi oldukça yüksek değerler vermektedir (Şekil 1). 


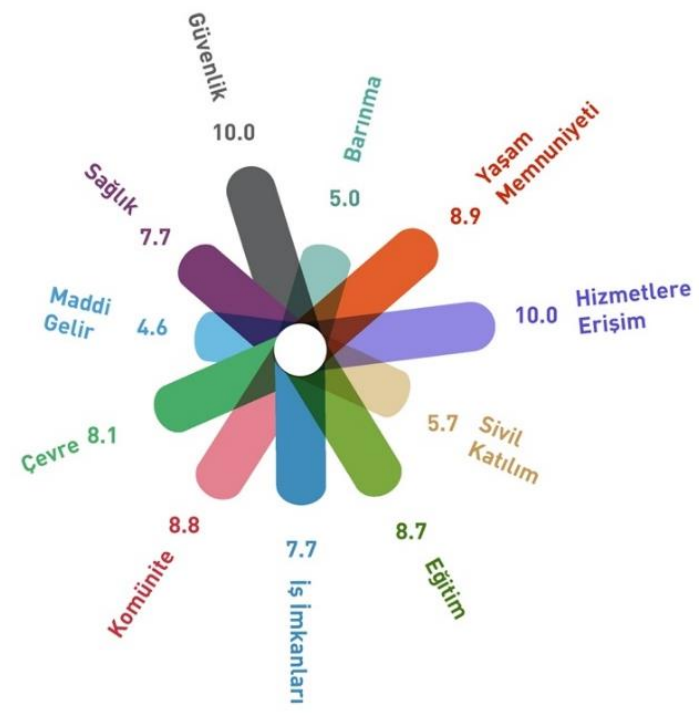

Şekil 1. Helsinki Uusima bölgesi kalkınma verileri üzerinden yazar tarafından görselleştirilmiştir (Organisation for Economic Co-operation and Development, 2020).

Çağdaş yaşam koşulları ve mimarlık alanındaki ileri teknik ve tasarım kültürü ile kentleşme üzerine etkin doneler sunan Helsinki kent merkezi, bu yönüyle araştırmanın örneklemini oluşturmaktadır. Helsinki'de 2013 yılından itibaren kentle ilgili kararlar kentlilere açık ve interaktif şekilde gerçekleştirilmektedir. Sürece katılım yarışma projeleri, çevrimiçi anketler, toplantılar, açık tartışma platformu olarak kullanılan bloglar ve çeşitli etkinliklerle sağlanırken, projelere ait materyaller internet üzerinden paylaşılmaktadır. Böylece kentlilerin bu dönüşümde söz sahibi olabilmesi için farklı ortamlarda konunun tartışılmasına imkân yaratılmaktadır. Tüm bu sürecin sonucunda 29 Ekim 2016'da Helsinki'nin kentlilerin denetiminden geçen yeni kent planı Helsinki Kent Konseyi tarafından onaylanmıştır (Helsinki Kent Planlama Departmanı, 2017). Bununla birlikte bir dizi kentsel düzenleme başlamıştır.

Helsinki Kent Planlama Direktörü Mikko Aho, kentin 2050 yılına kadar karbon nötr ve sürdürülebilir bir kent olma hedefinden bahsetmektedir. Bu amaçla, sürdürülebilir ulaşım koşulları ve çeşitli toplu taşıma sistemleri kentin her yerine kolayca ulaşımı sağlayacak şekilde geliştirilmektedir. Yürüme ve bisiklet yollarının bu alanda birincil öncelikte ele alındığı kentte, özellikle yeşil alanların korunduğu meydanlar ve parklar gibi kentlilerin bir araya geldiği buluşma noktalarının arttırıldığ (Helsinki Kent Planlama Departman1, 2017). 
Son yıllarda Helsinki'de kent ölçeğinde gerçekleştirilen ve mimari yarışmalarla tasarlanan Allas Deniz Havuzu, Oodi Helsinki Merkez Kütüphanesi gibi projeler, halkın hem kent merkezinde olup hem de doğal alanlar ve denizle yakın temas kurabileceği şekilde düzenlendiğinin göstergeleridir. 2017 yılında tamamlanan Allas Deniz Havuzu projesi, halka açık deniz havuzları, Fin hamamı, restoran ve kafe gibi hizmet alanlarını kapsayan geçici bir kentsel strüktürü Helsinki limanına yerleştirmiştir. 2018 yılında tamamlanan Oodi Helsinki Merkez Kütüphanesi ise yine kent merkezinde kamuya açık çalışma mekânları, bilgisayarlar, üç boyutlu yazıcılar gibi imkanlar sunan çok yönlü ve kapsamlı bir merkez olarak kurulmuştur. Yapının çevresi kentlilerin bir araya gelebileceği yeşil alanlar ve parklarla düzenlenmiştir. Benzer şekilde karbon nötr kent olma hedefi doğrultusunda 2029 yılından itibaren uygulanmak üzere kömür üretimini yasaklayan kent, Şubat 2020'de başvurularını açtığ 'Helsinki Energy Challenge' adlı uluslararası bir yarışma ile kentin enerji ihtiyacını sürdürülebilir yöntemlerle karşılamak için araştırmalarını sürdürmektedir (City of Helsinki, 2020a). Bu bağlamda Helsinki kenti, kentsel iç mekân ve kamusal mekân kavramlarını sürdürülebilir kentleşme odağında ele alan bu çalışma için uygun bir örnektir.

Helsinki kent merkezindeki Kamppi bölgesinde yer alan Lasipalatsi Meydanı, adını aldığı Lasipalatsi binasının müzeye dönüşüm projesi ile birlikte geleneksel kent meydanı özelliğinden ayrışarak kentsel bir iç mekân halini almıştır. Meydanın bu yeni kimliğini irdelemek için öncelikle meydanı oluşturan mimari öğeler, çevresiyle ilişkisi ve kent dokusuna katkısı üzerinde durmak gerekmektedir (Şekil 2). 


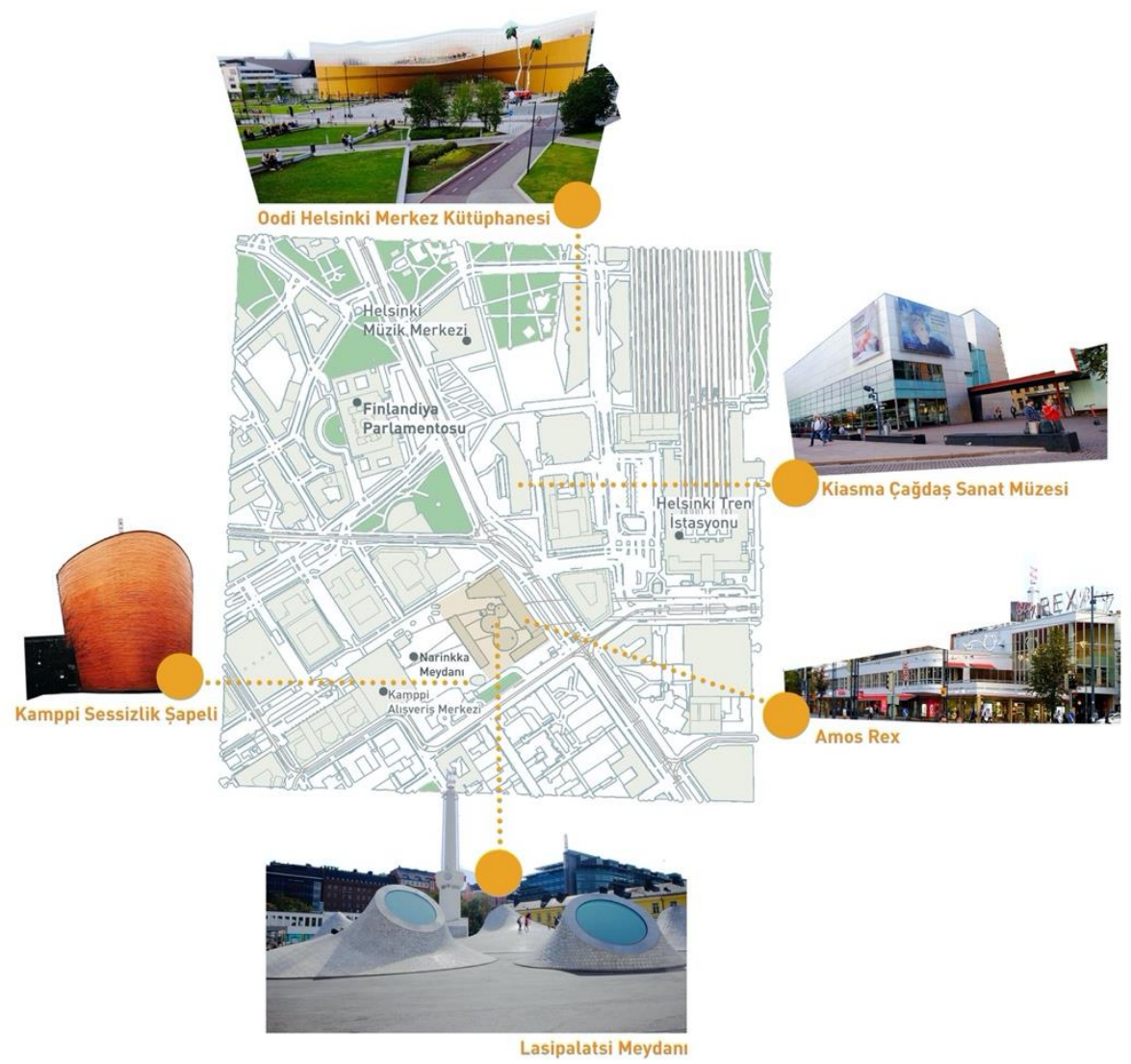

Şekil 2. Helsinki kent merkezi, Lasipalatsi Meydanı ve çevresi.

(Karayılanoğlu, 2019)

Lasipalatsi Fince'de "cam saray" anlamina gelmektedir. Meydana ismini veren Lasipalatsi binası 1936'da üç mimarlık öğrencisi Viljo Revell, Heimo Riihimäki ve Niilo Kokko tarafından, olimpiyatlarda kullanılmak üzere geçici bir yapı olarak tasarlanmıştır. İşlevine uygun şekilde, fonksiyonalist mimari üsluptadır. İçerisinde sinema, restoran, kafe, kış bahçesi ve dükkanlar olan yapı, inşa edildiği dönemde ilgi odağı haline gelmiş ve böylece kalıcı olarak kullanımı devam etmiştir. Helsinki'nin sembollerinden biri haline gelen yapı, 1965 yılından itibaren kapsamlı bir özel müze olan Amos Anderson Müzesi olarak kullanılmıştır (Amos Rex, 2020).

2013 yılında Föreningen Konstsamfundet Association tarafından Lasipalatsi Meydanı'nı da kapsayan bir proje ile binayı yenileme kararı alınmıştır (City of Helsinki, 2020b). Proje 2014 yılında Helsinki Kent Konseyi tarafından 
onaylanmıştır (City of Helsinki, 2016). Lisapalatsi binasının cephesi ve mimari kimliği korunarak, meydanın altındaki alana genişleyen bir yeraltı müzesinin tasarımı JKMM Architects tarafından gerçekleştirilmiştir (Amos Rex, 2020). Amos Rex'in inşası 2018 yılında tamamlanmış ve müze ziyarete açılmiştır.

Lasipalatsi Meydanı, Narinkka Meydanı ve Mannerheimintie Caddesi arasında yer almaktadır. Önceleri otobüs durakları olarak kullanılan Narinkka ve Lasipalatsi Meydanları, yayalaştırma politikası ile yapılandırılmış ve otobüs durakları bölgeden kaldırılmıştır (Şekil 3).

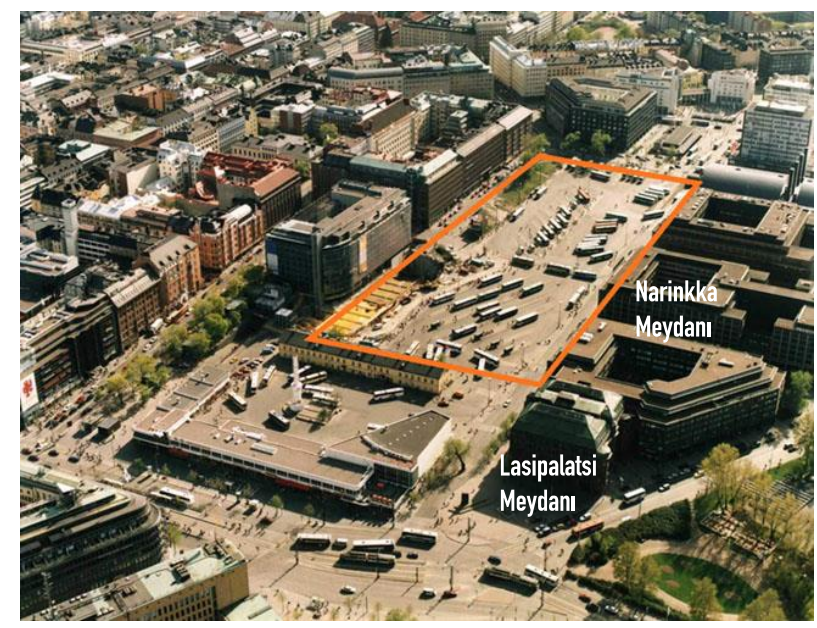

Şekil 3. Otobüs durakları olarak kullanıldığı dönemde Narinkka ve Lasipalatsi Meydanları (Public Space, 2006).

Narinkka Meydanı'nda hâkim yapı Kamppi Alışveriş Merkezi binasıdır. Mimarı Juhani Pallasmaa olan Kamppi Alışveriş Merkezi Helsinki kent meydanındaki ticari merkez olarak işlemektedir. İçerisinde otobüs terminali, yer altı metro istasyonu, yer altı otopark alanı, süpermarket, mağazalar, restoranlar, gece kulüpleri ve servis noktaları bulunan 6 katlı bir alışveriş merkezi olan yapı, aynı zamanda konut ve ofis mekânlarını da içermektedir. Narinkka Meydanı ve Lasipalatsi Meydanı'nı birbirinden ayıran kütle ise önceleri Helsinki merkez otobüs durakları hizmet binası olarak kullanılan, bugün ise içerisinde sergi, kültür merkezi, kafe ve bar gibi kamusal alanları barınd1ran çok işlevli bir yapıdır.

İki meydanı birbirine bağlayan mimari öğelerden bir diğeri de Kamppi (Sessizlik) Şapeli'dir. Yapı, bir yarışma projesiyle tasarlanmıştır. Eğimli ahşap 
cephesiyle, küçük dairesel formlu şapel, kent merkezinde anıtsal bir nitelik taşımaktadır. Her yönden yaklaşılabilen yapı, ziyaretçilerini yumuşak eğilimli formuyla Narinkka Meydanı'ndan Lasipalatsi'ye nazikçe yönlendiren bir etkiye sahiptir. Kentsel bir odak oluşturma noktasında bulunduğu çevreye yeni bir kimlik katarken, mimari formu ile çevresine kontrast oluşturarak öne çıkmaktadır.

Lasipalatsi binası ön cephesi, Mannerheimintie yönünde, Steven Holl'un tasarımı olan Kiasma Çağdaş Sanat Müzesi ile karşı karşıyadır. Kiasma'nın yanı başında ise Oodi Helsinki Merkez Kütüphanesi ve Helsinki Müzik Merkezi yer almaktadır. Bu anlamda bölgenin kültür ve sanat merkezi olarak kurgulandığı görülmektedir.

Lasipalatsi Meydanı için belirlenen yeni kimlik, tarihsel bağlamıyla ilişkili biçimde katmanlıdır. Üç ayrı dönemde farklı işlevlerle kullanılan Lasipalatsi'nin tarihsel kimliği, Amos Rex'e dönüşümüyle birlikte büyük oranda korunmuştur. Meydanın batı yakasında yer alan 20. Yüzyıl üretimi yapı, iç mekânda güncel işlevi çerçevesinde yenilenmiştir. Eski mimari kimliğine ait öğeler günümüzde hala belirgin durumdadır. Mevcut yapıda sürdürülen bu katmanlı yaklaşım, Lasipalatsi Meydanı'na eklemlenen yeni kimlikte de kendini göstermektedir. Meydanın kazılması ile altında oluşturulan alan, var olan yapıya bağlanan bir yeraltı müzesi olarak kurgulanmıştır. Yapay topografik yükseltiler şeklinde inşa edilen, çelikle güçlendirilmiş betondan kubbeler, meydanın altında oluşturulan galeri mekânları ile katmanlı bir bağ kurmaktadır (Şekil 4).

Yayaların geçişine izin verecek şekilde tasarlanmış kıvrımll, topografik kubbeler, üzerinde oturulabilen tribünler, sahneler veya platformlar olarak hizmet edebilmektedir. Bu bağlamda aynı zamanda akışkan bir kent mobilyası işlevindedir. Farklı etkinliklerde gerekli geçici yapıları kurmak gibi çok işlevli olarak kullanılabilmesi için meydanın geniş bir bölgesinin, özellikle Turku Kışlası tarafında, düz alanlar olarak bırakıldığı görülmektedir. Bu yönüyle kubbelerle bir anlamda kullanım alanları kısitlanan meydan, baskın olarak müzenin varlığına işaret etmekle birlikte, diğer etkinlikler için de uygun kılınmıştır. 

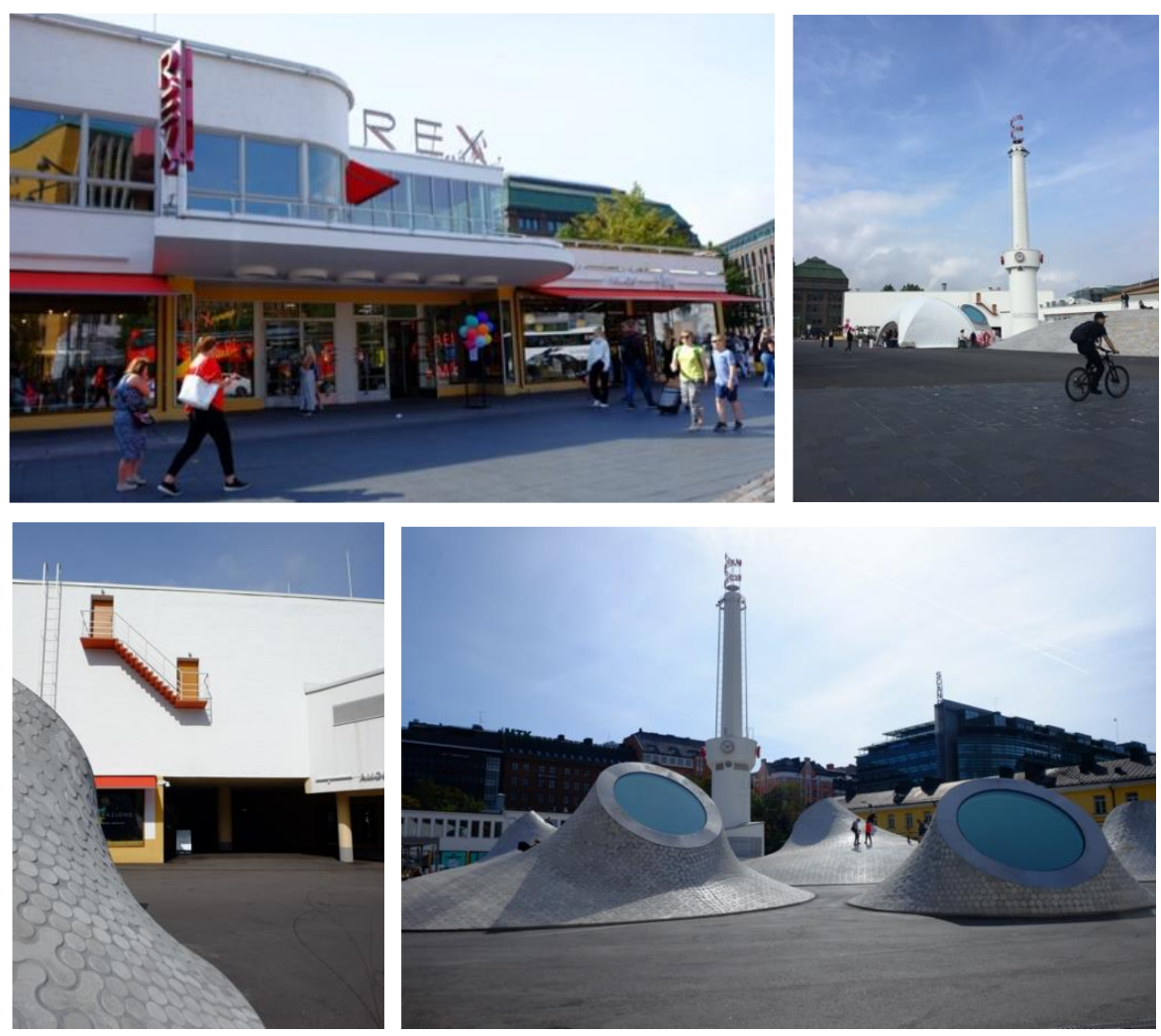

Şekil 4. Amos Rex ve Lasipalatsi Meydanı'nın farklı açlardan görünümü.

(Karayılanoğlu, 2019)

Müzeye yaya girişi, Lasipalatsi binası ile meydan ve caddede iki ayrı yönden sağlanmaktadır. Bu bağlamda yapıya hem cadde hem de meydan yönünden yaklaşılabilmekte ve yapı meydanla cadde arasında bir arayüz halini almaktadır. Girişte bilet satış ve resepsiyon ile birlikte bir kafe alanı yer almaktadır. Galeri alanları alt katta kurgulanırken, yapının üst katında bir restoran bulunmaktadır. İç mekânda, girişten itibaren hem cadde hem de meydan yönündeki geniş açılıklar sayesinde kentle görsel temas sürmektedir. Belirli yönlerde kasıtlı olarak açılan çatı pencerelerinin, meydanın ortasındaki saat kulesi ya da cephedeki merdiven gibi çevrenin tanınabilir ayrıntılarına yönlendirildiği görülmektedir. Bu sayede yeraltı müzesi ve çevresindeki şehir arasında görsel bir temas kurulmaktadır (Şekil 5). 

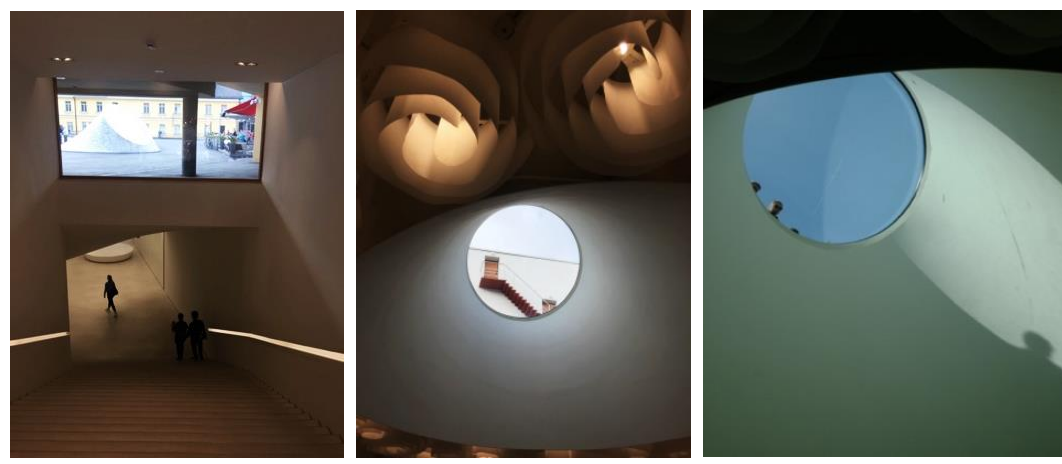

Şekil 5. İç mekândan cephe ve çatı pencereleri ile kentle kurulan görsel temas.

(Karayılanoğlu, 2019).

Cadde kotunun altında kalan galerilerde kubbeli çatı pencereleri ile gün ışığı iç mekâna alınmaktadır. Bu pencereler serginin içeriğine göre gerektiğinde 1şığı geçirmeyecek şekilde kapatılabilmektedir. Meydandaki sarmal saat kulesi ve cephedeki merdiven gibi bölgeye ve yapıya ait sembolik öğelere yöneltilen bu açıklıklar hem dişarıyı içeriye taşımakta hem de bu öğeleri iç mekânda odak noktası haline getirmektedir. Açık planlı, geniş galeri mekânları etkileyici bir mekân deneyimi sunmaktadır (Şekil 6).
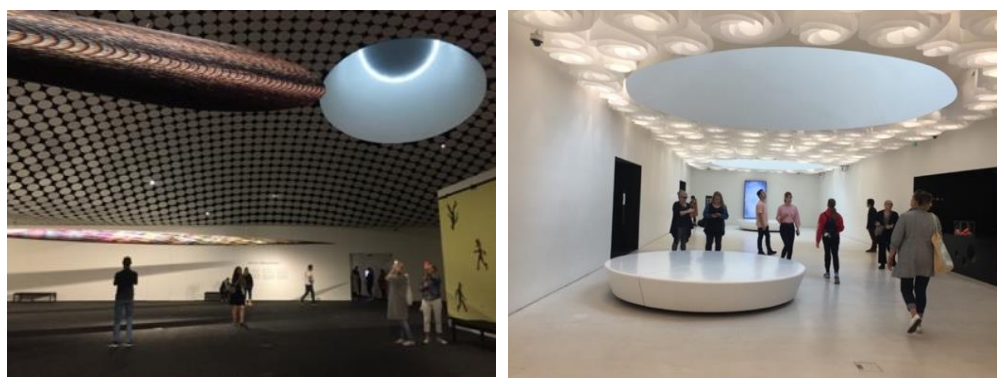

Şekil 6. Amos Rex Yeraltı Müzesi galerilerinde genel atmosfer.

(Karayılanoğlu, 2019).

\section{Tartışma ve Sonuç}

Bu çalı̧̧ma kapsamında kentsel bir iç mekâna dönüşen Lasipalatsi Meydanı ve Amos Rex Yeraltı Müzesi özelinde Helsinki kent merkezi sürdürülebilir kentleşme bağlamında incelenmiştir. Araştırmanın strüktürü üç temel araştırma sorusu ekseninde gelişmiştir. Bunlar; sürdürülebilir kent politikaları kapsamında tasarlanan kent meydanındaki çok işlevli dönüşümün özellikleri, kamusal iç mekân ve kentsel iç mekân arasındaki sınırların hangi yöntemlerle silikleştiği ve katmanlı bir mekân deneyiminin koşullarının neler olduğudur. 
Sürdürülebilir kentleşme; çevreye duyarlı enerji tüketimi, atık ve enerji döngüsünü sağlayan ekonomi modelleri, enerji verimli ulaşım sistemleri, kültürel ve ekonomik kalkınma, kapsayıcı ve çok sesli karar mekanizmaları oluşturulması gibi çok kapsamlı ve pek çok parametreyi içerisinde barındıran bir denklemdir. Kent meydanlarının kültürel kalkınma ile dönüşümü, kentlilerin fikirleri ve istekleri doğrultusunda şeffaf bir karar sürecinden geçirilmesi ile gerçekleştiğinde, kalıı ve kapsayıcı çözümler sunmaktadır.

Bir yeniden işlevlendirme projesi olan bu dönüşüm, sürdürülebilir kentleşmenin temel adımlarından birini doğası gereği sağlamaktadır. Zaman içerisinde kullanım amacını yitiren yapıların kültürel miras değeri ve kent hafızasındaki yeri göz önünde bulundurularak yeniden işlevlendirilmesi sürdürülebilir kalkınmayı desteklemektedir. Bu dönüşüm süreci yapının tarihsel kimliğinin korunması ile gerçekleştirildiğinde, kentlilerin yapı ile kurdukları bağ korunmakta ve yapı aynı zamanda çağdaş ihtiyaçlara hizmet edebilmektedir. Bu bağlamda Lasipalatsi binasının Amos Rex'e dönüşümünde yapı kimliğine ait belirgin öğelerin hem meydanda hem de yapı kabuğu ve iç mekânında korunması bu hassasiyeti ortaya koymaktadır.

Bir kentsel iç mekân olarak Lasipalatsi Meydanı bugünkü haliyle içe dönük bir odak noktası görünümündedir. Lynch'e göre “Çevre, görsel olarak düzenlenmiş ve keskin bir şekilde tanımlanmış ise, kentli de kendi anlamlandırması ve oluşturduğu bağlantılarla kente şeklini verir. Isşte o zaman kent, dikkat çekici ve kolay tanımlanabilir gerçek bir yer olabilir."(Lynch, 2010, s. 102). Bu bağlamda Amos Rex Yeraltı Müzesi'nin Lasipalatsi Meydanı ile kurduğu bağ, Helsinki kent kimliğinde akılda kalıcı bir yer bulmaktadır. Alışılagelmişten farklı bir kamusal alan deneyimi sunmakla birlikte, meydanın yeni hali, kullanım alanı ve işlevinin sınırlanması yönüyle eleştiriye açıktır. Ancak bu durum kent ölçeğinde ele alındığında hemen yanında yer alan ve çok daha geniş bir toplanma alanı sunan Narinkka Meydanı'nın varlığı bu eksiği kapatmaktadır. Bu yönüyle, kültür-sanat etkinlikleri ve oyuncu bir kent kullanımını bir araya getiren kentsel iç mekân kimliği Lasipalatsi' de baskın hale gelmektedir.

Meydandaki topografik yükseltiler ve müze galerilerine bakan tepe pencereleri ile merak uyandıran, ilgiyi müze mekânına yönelten bir etki mevcuttur. Bu durum aynı zamanda oluşturulmak istenen kent kimliğiyle ilgili önemli bir söylemdir. Kamusal alanın kültür mekânının ışığıyla aydınlandığı, temellerinde sanatın yer aldığı bir kent meydanı Helsinki'nin mimarlık ve sanat odaklı kent kimliğine işaret etmektedir. Sembolik niteliğinin yanı sıra, işlevsel yönü ile de çoğulculuğa vurgu yapmaktadır. Kubbelerin akışkan 
formu, her yönden kendisine yaklaşılabilen bir kent mobilyası olarak kullanılmaktadır. Her yaştan kentlinin bir noktasından deneyimleyebileceği farklı kotlarla kentlilere her seferinde farklı açlardan kenti deneyimleme zemini sunarken, alternatif etkinliklere de ortam sağlamaktadır.

Araştırma sonucunda, Helsinki kent meydanındaki çok işlevli dönüşümün yeniden işlevlendirme, kültürel kalkınma, yayalaştırma, yeni kentsel odaklar oluşturma, mekân algısı ve kapsayıcı kent mobilyalarıyla kentli ve kent arasında etkileşimi arttırma gibi çok katmanlı ilişkileri kapsadığı görülmüştür. Helsinki'de benimsenen sürdürülebilir kent modeli, kapsayıcı, katılımcı, çok sesli, insan odaklı bir karar verme süreci ile başlamaktadır. Bu süreç çevresel duyarllık ve kültürel kalkınma ile desteklenmektedir. Sürdürülebilir kalkınma planı çerçevesinde Helsinki kent merkezinde ulaşımın bisikletli ve yayalar için kolaylaştırıldığı bir sisteme evrildiği görülmektedir. Bu bağlamda kent meydanında insan odaklı dönüşümlerin yanı sıra kapsamlı kültür yapılarının sayısının da arttırıldığı tespit edilmiştir. Yayalaşan, kapsayıcı, kültürel kimliğini ön plana alan kent, bu kimliği meydanlarında baskın olarak ortaya koymaktadır.

Kamusal iç mekân ve kentsel iç mekân arasındaki sınırların hangi yöntemlerle silikleştiği ise bu kavramların literatürdeki tanımları ve Lasipalatsi örneğindeki dönüşümü üzerinden incelenmiştir. Elde edilen verilere göre, kentsel iç mekân kavramının kullanıcının algısıyla şekillendiği ve bu algının mekânsal ölçekle pekiştiği görülmektedir. Kamusal mekânın en belirgin örneklerinden biri olan kent meydanında kentsel iç mekâna dönüşüm süreci öncelikle meydanın yayalaştırılması ile başlamaktadır. Bu algıyı, meydana eklemlenen kent mobilyaları ve meydanı çevreleyen diğer öğeler desteklemektedir. Bir arada olmanın, sosyalleşmenin, ortak paylaşımın mekânları olan kamusal mekânların ortak kültürü temsil eden bir kimlikle dönüşümü kent meydanının özünü kaybetmemesini sağlarken, sürdürülebilir kentleşme için kilit noktalardan biri olan kültürel kalkınmaya da destek olmaktadır.

Lasipalatsi Meydanı ve Amos Rex Yeraltı Müzesi örneğinde, kent meydanının kentsel iç mekâna dönüşümü bölge kimliği yitirilmeden, meydanı kentlilere açan bir yaklaşımla sağlanmıştır. Kent planlamasındaki toplum ve kültür odaklı, şeffaf ve demokratik yaklaşım müzenin tasarımına yansımıştır. Müzenin meydanla olan ilişkisini sürdüren bir tasarımla bölge kentsel iç mekân halini alarak katmanlı bir mekânsal deneyim sunmaktadır.

Araştırmada kentsel iç mekâna dönüşen kent meydanı yalnızca bir örnek üzerinden incelenmiştir. Bu anlamda çalışma gelişime açktır. Gelecekte ya- 
pılacak çalışmalarda, bu çalışmanın teorik altyapısı kullanılarak farklı kentlerden örneklerle araştırma geliştirilebilir. Kentlerin diğer bölgelerinin sürdürülebilir kentleşme bağlamında kentsel iç mekâna dönüşümünü araştıran çalışmalar yapılarak mimarlık alanına yeni katkılar sunulabilir. 


\title{
Extended Abstract
}

\section{Transformation of Public Space into Urban Interior on the Axis of Sustainable Urbanization: The Case of Helsinki}

\author{
Gamze Karayılanoğlu \\ ORCID: 0000-0002-7874-4902
}

Considering the constantly changing urban needs and user diversity, the importance of sustainable urbanization is critical. One of the main issues that come to the fore within the framework of the "Sustainable Development Goals" that the United Nations aims to realize by 2030 is cultural development. In this context, museums, which are the leading public spaces in the transfer of culture, have critical importance in the foresight of sustainable urbanization.

Within the scope of this study, the relationship between the museum as a public interior space, and the city square as an urban interior, is discussed in the context of sustainable urbanization. Lasipalatsi Square and Amos Rex Underground Museum, located in Helsinki, were selected for their unique and layered relationships at the urban interior-public space intersection. Therefore, a case study was conducted through a comprehensive literature review and field research. In this respect, the Helsinki city center provides extensive data on its developed living conditions, advanced technology, and design culture.

This study questions the concept of space in order to define what makes interior or exterior space prior to the definitions of public space, public interior, and urban interior. Public space defines a common area that includes public interiors. They can be outdoor spaces as well as interiors that are mostly institutional and public. Movie theaters, museums, cafes, restaurants, libraries are among the public interiors. The unifying effect of public space continues in these spaces. When public interiors intersect with urban space, they form a liminal zone. The contrast of exterior and interior space unites in 
perception. The urban interior concept is nourished by this in-between situation. It is an urban phenomenon in which the public and open spaces become an interior space in perception by relating to its surroundings. Public spaces such as city squares, spaces between buildings, idle spaces between the columns of a viaduct are some of the examples of urban interiors.

During the research process, three fundamental research questions shaped the structure of the study. What are the characteristics of the multifunctional transformation in the city square designed within the scope of sustainable urban policies? In what ways do the boundaries between the public interior and the urban interior fade? And lastly, what are the conditions for a layered spatial experience?

It has been observed that the multifunctional transformation in the Helsinki's public square designed within the scope of sustainable urban policies. These includes multi-layered relationships such as adaptive reuse, cultural development, pedestrianization, creating a new urban focus, increasing the interaction between the city and the citizens with the perception of space and inclusive urban furniture.

According to the data obtained, the urban interior is defined by the relations of the spatial elements perceived in the built environment. In Lasipalatsi, the underground museum transforms the public square into an urban interior visually and tactually. Decisions such as providing access to Lasipalatsi Square from the main street through the museum building as an intersection contributes to this perception.

The historical identity of the Lasipalatsi building has been preserved to a great extent. The 20th-century building has been renovated within the framework of its current function as a museum. However, the elements of the previous architectural identity are still evident. This layered approach maintained in the current structure also manifests itself in the new identity articulated in Lasipalatsi Square.

The area excavated under the square was designed as an underground museum connected to the existing building. The artificial topographic domes built with steel-reinforced concrete establish a layered connection with the gallery spaces through the skylights. There is an intriguing effect in the public square, with domes and skylights overlooking the museum galleries, directing attention to the museum space. The domes are directed to the symbolic elements of the area, such as the spiral clock tower in the middle of the Lasipa- 
latsi Square and the staircase on the façade. Consequently, the outside is reflected in the interior space and becomes the focal point. Open-plan, spacious galleries offer an impressive spatial experience.

After its transformation with Amos Rex, Lasipalatsi Square has become an urban interior. Both the relationship of the Lasipalatsi building with its surroundings and its function as an interface while entering the square support this perception. Moreover, the domes also create an approachable, tactile environment. Thus, the citizens can catch a sight of the interior of the underground museum from the square. This unique relationship with the public square and interior space help create urban interior perception.

A city square, where the public space is illuminated with the light of the cultural space and where art is at its foundations, points to Helsinki's urban identity focused on art and culture. In addition to its symbolic nature, it emphasizes pluralism with its functional aspects. The fluid formed domes are used as urban furniture that can be approached from all directions. The domes function as a platform to experience the city from different angles. In this way, it creates an environment for alternative activities. The project also checks the basis of sustainable urbanization due to being an adaptive reuse project.

The public and culture-oriented, transparent, and democratic approach in urban planning is also reflected in the museum design. This design approach continues in the public square. Therefore, the public square becomes an urban interior and offers a layered spatial experience.

In conclusion, the sustainable city model adopted in Helsinki starts with an inclusive, participatory, polyphonic, people-oriented decision-making process. The process is supported by environmental awareness and cultural development. Pedestrianized, inclusive cities that emphasize cultural development, display this approach predominantly in city squares. The change in the Helsinki city center reveals the importance of culture-oriented design in urban spaces.

\section{Kaynakça/References}

Akarsu, B. (2014). Kant'ta mekân ve zaman kavramları. İstanbul Üniversitesi Felsefe Arkivi Dergisi, 14, 108-122.

Altınyıldız Artun, N. (2014). Sürrealizm mimarlk: Mekân sanatı. İstanbul: İletişim Yayınları.

Amos Rex. (2020). Architecture. 12.10.2020 tarihinde https://amosrex.fi/en/aboutus/architecture/ adresinden erişilmiştir. 
Archer, J. (2005). Social theory of space: Architecture and the production of self, culture, and society. Journal of the Society of Architectural Historians, 64(4), 430-433. doi:10.2307/25068197.

Attiwill, S. (2011). Urban interior: Informal explorations, interventions and occupations, Ed. Rochus Urban Hinkel, Art, Architecture, Design Research (AADR) Publications, Baunach: Spurbuchverlag Publishing House of AADR, 11-24.

Bala, H.A. (2006). Mimarlık- şehircilik, bina- kent, iç- dış, özel- kamusal arasında kentsel arayüzler. Yapı Dergisi, 293. http://www.yapi.com.tr/haberler/mimarlik---sehircilik-bina---kent-ic---dis-ozel---kamusal-arasinda-kentsel-arayuzler_61114.html adresinden erişilmiştir.

City of Helsinki. (2016). New Amos Anderson museum named Amos Rex. 12.10.2020 tarihinde https://www.hel.fi/uutiset/en/helsinki/amos-rex adresinden erişildi.

City of Helsinki. (2020a). Helsinki energy challenge: Finding the future of heating, 23.10.2020 tarihinde https://www.myhelsinki.fi/en/think-sustainably/helsinkienergy-challenge-finding-the-future-of-heating adresinden erişilmiştir.

City of Helsinki. (2020b). Lasipalatsi. 12.10.2020 tarihinde https://www.myhelsinki.fi/en/see-and-do/sights/lasipalatsi adresinden erişilmiştir.

Corbusier, L. (1978). Towards a new architecture. Londra: The Architectural Press. (Orijinal basim tarihi 1929).

Cordan, Ö., ve Çolak, Ş. (2015). İç ve dış arasında mekânsal ve toplumsal bir karşılaşma durumu olarak “Kentsel iç mekân”, Mimarlık Dergisi, 384.

Gardner, G. (2016). Toward a vision of sustainable cities. State of the World Can a City Be Sustainable? İçinde (s.45-46).Washington: Island Press

Gökgür, P. (2008). Kentsel mekânda kamusal alanın yeri. İstanbul: Bağlam Yayıncılık.

Harteveld, M., ve Brown, D.S. (2007). On public interior space. AA Files 56. Londra: Architectural Association Publications, s. 64-73.

Helsinki Kent Planlama Departmanı. (2017). Helsinki city plan : Helsinki is growing sustainably. 01.11.2020 tarihinde https://www.hel.fi/hel2/ksv/julkaisut/esitteet/esite2017-1-en.pdf adresinden erişildi.

Holl, S. (2000). Parallax. Birkhauser, Basel, Boston, Berlin: Publishers for Architecture. International Council of Museums. (2019). Museum Definition, 09.10.2020 tarihinde https://icom.museum/en/resources/standards-guidelines/museum-definition/ adresinden erişildi.

Jarvie, J. ve Friend, R. (2016). Urbanization, inclusion, and social justice. Mastny, L. (Ed.), Can a City Be Sustainable? Worldwatch Institute, Island Press, Washington.

Kahvecioğlu, H. (1998). Mimarlıkta imaj: Mekânsal imajın oluşumu ve yapısı üzerine bir model. Doktora Tezi, İstanbul Teknik Üniversitesi, Fen Bilimleri Enstitüsü, İstanbul.

Lefebvre, H. (2014). Mekânın üretimi. İstanbul: Sel Yayıncılık.

Lynch, K. (2010). Kent imgesi. İstanbul: Türkiye İş Bankası Kültür Yayınları.

Nalbantoğlu, H.Ü. (2008). Nedir mekân dedikleri? III. Disiplinlerarası Mimarlık Felsefe Toplantısı: Zaman-Mekân, Mekân-Zaman, 18-19 Kasım 2005, İstanbul, 88-105. 
Odabaş, U.K., (2018). Tarihsel Süreçte kamusal alanın yapısal dönüşümü ve Habermas. Atatürk Üniversitesi Sosyal Bilimler Enstitüsü Dergisi, 22(Özel Say1): 2051-2066.

Organisation for Economic Co-operation and Development. (2019). Regional outlook 2019, Finland. 23.10.2020 tarihinde http://www.oecd.org/cfe/_Finland.pdf adresinden erişildi.

Organisation for Economic Co-operation and Development. (2020). Regional, rural and urban development. 23.10.2020 tarihinde http://www.oecd.org/regional/ adresinden erişildi.

Özyörük, İ. (1995). The interface of architectural built form and urban outdoor space. Yüksek Lisans Tezi, Orta Doğu Teknik Üniversitesi, Graduate School of Natural and Applied Sciences, Ankara.

Poot, T., Van Acker, M. ve De Vos, E. (2015). The public interior: The meeting place for the urban and the interior, Idea Journal 2015 Urban + Interior, 44-55.

Public Space. (2006). Underground complex in Kamppi centre. 11.10.2020 tarihinde https://www.publicspace.org/works/-/project/d169-underground-complex-inkamppi-centre adresinden erişildi.

United Nations Development Programme. (2016). Sürdürülebilir kalkınma amaçları. 10.10.2020 tarihinde https://www.tr.undp.org/content/turkey/tr/home/sustainable-development-goals.html adresinden erişilmiştir.

United Nations Educational, Scientific and Cultural Organization. (2019). Culture and sustainable development. United Nations. 10.10.2020 tarihinde https://en.unesco.org/system/files/private_documents/un_report_-_2019.pdf adresinden erişilmiştir.

United Nations. (2016). The United nations conference on housing and sustainable urban development. 10.10.2020 tarihinde http://habitat3.org/wp-content/uploads/NUATurkish.pdf? $\mathrm{v}=2$ adresinden erişildi.

Zevi, B. (1957). Architecture as space. New York: Horizon Press. 